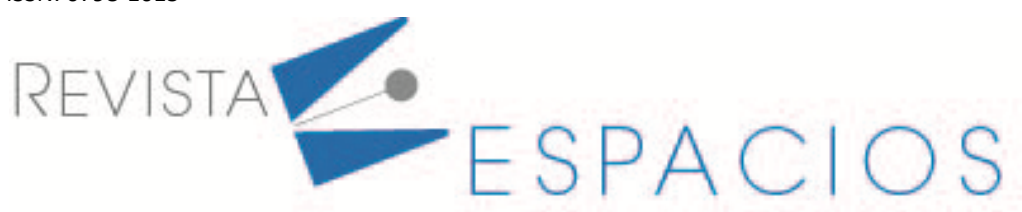

Vol. 42 (02) $2021 \cdot$ Art. 6

\title{
Formation of a model for predicting the behavior of an enterprise in an unstable economic environment
}

\section{Formación de un modelo para predecir el comportamiento de una empresa en un entorno económico inestable}

\author{
KUZUBOV, Alexey A. ${ }^{1}$ \\ MAKSIMENKO, Aleskandr N. ${ }^{2}$ \\ KHLOPENKO, Oksana V. ${ }^{3}$ \\ BEZUGLOVA, Margarita N. ${ }^{4}$
}

\begin{abstract}
This article is devoted to the formation of a forecasting model for an enterprise in the context of unstable economic relations. Based on the analysis of literary sources, the concept of enterprise development and its behavior was considered, and three main approaches to the study of indicators of enterprise behavior were identified. The interrelation of the factors of the system of models for predicting the behavior of the enterprise has been formed. A system of analytical functions has been developed that create the structure of a model for predicting the behavior of an enterprise, which will allow analyzing the internal capabilities of an enterprise to changes in the external environment.

Key words: enterprise behavior, modeling, external environment, forecasting

Resumen

Este artículo está dedicado a la formación de un modelo de pronóstico para una empresa en el contexto de relaciones económicas inestables. A partir del análisis de fuentes literarias, se considera el concepto de desarrollo empresarial y su comportamiento, y se identifican tres enfoques principales para el estudio de indicadores de comportamiento empresarial. Se ha formado la interrelación de los factores del sistema de modelos para predecir el comportamiento de la empresa. Se ha desarrollado un sistema de funciones analíticas que crea la estructura de un modelo para predecir el comportamiento de una empresa, lo que permitirá analizar las capacidades internas de una empresa ante cambios en el entorno externo

Palabras clave: comportamiento empresarial, modelado, entorno externo, previsión
\end{abstract}

\section{Introduction}

The key concepts of the set scientific problematics, which make it possible to position it, on the one hand, in the conceptual and categorical field of economic science, and on the other, in the context of increasing the level of enterprise efficiency, should be considered economic indicators, a model and forecasting of economic processes.

\footnotetext{
${ }^{1}$ Candidate of Economic Sciences, associate Professor of Economics, Don state Technical University, Rostov-on-Don, E-mail: alexceyk@gmail.com

${ }^{2}$ Candidate of Economic Sciences, associate Professor of Economics, Don state Technical University, Rostov-on-Don, E-mail: MANzel@yandex.ru

${ }^{3}$ Candidate of Economic Sciences, associate Professor of Economics, Don state Technical University, Rostov-on-Don, E-mail: ohlopenko@yandex.ru

${ }^{4}$ Candidate of Economic Sciences, associate Professor of Economics, Don state Technical University, Rostov-on-Don, E-mail: margarita-b-85@mail.ru
} 
Economic indicators are used for planning, forecasting and analyzing the organization of production and labor, product quality, the use of fixed and circulating assets, labor and innovation resources. They are the basis for the development of a technical and economic plan of the enterprise, the establishment of progressive norms and standards of an economic nature, and the like. They can be general and specific, reflecting the characteristics of individual industries.

Forecasting any factor in the economic environment is impossible only on the basis of assessing the trend of the factor itself; for a clearer forecast, it is advisable to build a model that highlights a large number of external and internal factors. The success of the enterprise, its behavior in the market depends on the clarity of forecasts.

So, at any enterprise there is a problem of building a model for predicting the behavior of the enterprise, which most optimally solves the assigned tasks, especially in today's unstable market conditions.

\subsection{Literature Review}

Analysis of literary sources made it possible to determine three main approaches to the study of indicators of enterprise behavior, the basis of systematization of which was the result of the enterprise.

The first approach is based on the study of general performance indicators of the enterprise, which are manifested in the external environment. The authors who support this approach (Arefieva, Poberezhnaya, 2019. Azaryan, Alekseeva, 2018. Budagov, Gagulina, Zhulega, Novikov, 2019) determine that the general indicators of the enterprise's behavior are the resultant factors of all its activities, therefore it is advisable to diagnose the behavior of the enterprise according to these indicators, and provides complete information about his behavior.

This approach allows us to offer the following system of indicators of enterprise behavior:

- productivity as the ratio of the volume of commercial products to its production cost, including administrative costs;

- profitability (profitability) of current activities as the ratio of profit from sales and cost of sales;

- profitability as a ratio of cash inflow and outflow by type of activity and the whole enterprise.

The second approach is based on considering an enterprise not only as a set of economic indicators, but also as a behavioral object that has morality, functions of economic culture, psychological behavior, creative character, market orientation, rules of behavior, and leadership motivation.

Enterprise behavior is based in this approach mainly on socio-cultural and socio-psychological factors. This approach is implemented in works (Goral, 2019. Gutieva, 2017. Dementyev, 2018), which generalized these factors.

The third approach to constructing a system of indicators is based on the authors' concentration on various aspects of the behavior of enterprises in a market environment. So, in the works (Dilovskaya, 2017. Maksimenko, Malinina, 2018), an analysis of indicators of entrepreneurial behavior is carried out, (Zhukova, Arefieva, 2017) focus on the financial aspect of behavior, (Zanikyan, Kuropatkina, 2019) highlights the institutional and evolutionary behavior aspects, ( Zilberstein, Shklyar, Ershova, Rutskiy, 2017. Ivanenko, 2017) highlight the aspect of social responsibility (Shashlo, Kuzubov, Wildemann, 2017. Orlov, Sharko, Havenko, Husak, 2020) analyzes the market state of enterprises in the context of their competitiveness. In the works (Lviv, 2020. Malinina, Kushnareva, Maksimenko, 2019. Osipov, Shashlo, Kuzubov, 2017), the priority of the organizational structure and organizational behavior of the enterprise is highlighted. (Paikin, 2017) determines the indicators of enterprise behavior from the standpoint of a crisis state, (Remadze, Beloborodova, Grigorieva, Abutalipova, 2018) uses indicators of financial components as a space of indicators for studying enterprise behavior. An 
abundance of works is devoted to indicators that form the economic security of an enterprise (Sanakoeva, Gagieva, 2017. Subachev, Afonina, 2017. Chebykina, 2017).

\subsection{The aim of the article}

The purpose of this study is to build a system of models for predicting the behavior of an enterprise in terms of its interaction with the external environment, aimed at maintaining, adjusting a reasonable trajectory of its development.

To achieve the goal, this study proposes a solution to a number of problems, namely:

- substantiation of the method for constructing economic and mathematical models for predicting the behavior of an enterprise;

- formation of a methodological basis in the form of rules for constructing a predictive model of enterprise behavior;

- formation of a system of models for predicting enterprise behavior in the form of analytical functions.

\section{Methodology}

An important part of the methodological basis of the study is a reasonable choice of the method of economic and mathematical models, which forms the basis for building a complex of models, predicting the behavior of an enterprise. In this study, the choice of a method for developing a predictive model system is based on the following statements:

- the object of the study is enterprises in the real sectors of the economy, that is, enterprises that manufacture products. Therefore, to determine the relationship between resources (labor and capital) and the volume of output, it is advisable to use production functions;

- the tendency of change in the values of the indicators of the enterprise has a long-term memory. Long-term memory necessitates the use of autoregressive models by including lagged variables in predictive models;

- the enterprise is an open system.

The openness of the system predetermines the presence of cointegration links between the internal and external environment of the enterprise, which makes it expedient to use a system of vector autoregressive models.

Thus, the paper proposes to use the method of econometric modeling.

\section{Results}

Enterprise behavior is a complexly structured definition that is similar to the concept of development, but has its inherent features. If development in a broad sense is the attraction of future changes in time, then the behavior of an enterprise is its reactionary activity to the current influences of the external and internal environment, which is aimed at achieving the goals of functioning and development.

That is, on the one hand, behavior is a structural element of development, and on the other, behavior includes a number of short- and medium-term measures to achieve development goals. Thus, the concept of the development of an enterprise and its behavior are very related, therefore it is advisable to distinguish between the definition of the essence of these definitions. 
Thus, the development of an enterprise should be understood as the process of permanent changes in the goals of the functioning of an enterprise, which corresponds to the principle of goal-setting (Gutieva, 2017). Enterprise behavior is the reaction of the enterprise to regular changes in the internal and external environment of the enterprise in order to achieve its operational and tactical goals. The relationship between the behavior of the enterprise and its development is shown in Fig. one.

To build a model for predicting the behavior of an enterprise, first of all, it is necessary to determine what are the elements of the system, and what creates its structure. The elements of the model are factors and groups of factors that: characterize the activities of the enterprise (the first block of factors); characterize the relationship of the enterprise with the external environment (second block of factors), reflect the influence of the external environment (third block of factors).

The first block of factors includes integral indicators of the enterprise's behavior by its components:

$I_{o b}, I_{\text {fin }}, I_{\text {proiz }}, I_{\text {trud, }} I_{\text {inv }}$ - integral indicators of the level of development of the proposed components of the enterprise's behavior (respectively, components: the image of the enterprise in a competitive environment, the financial activity of the enterprise, the production activity of the enterprise, labor activity, innovation).

The second block of factors consists of: a factor reflecting the interaction of an enterprise with the external environment - the volume of production $(\mathrm{Y})$, and factors characterizing the manageability of an enterprise - the volume of labor and capital resources ( $\mathrm{L}$ and $\mathrm{K}$, respectively).

Figure 1

The relationship between behavior and enterprise development
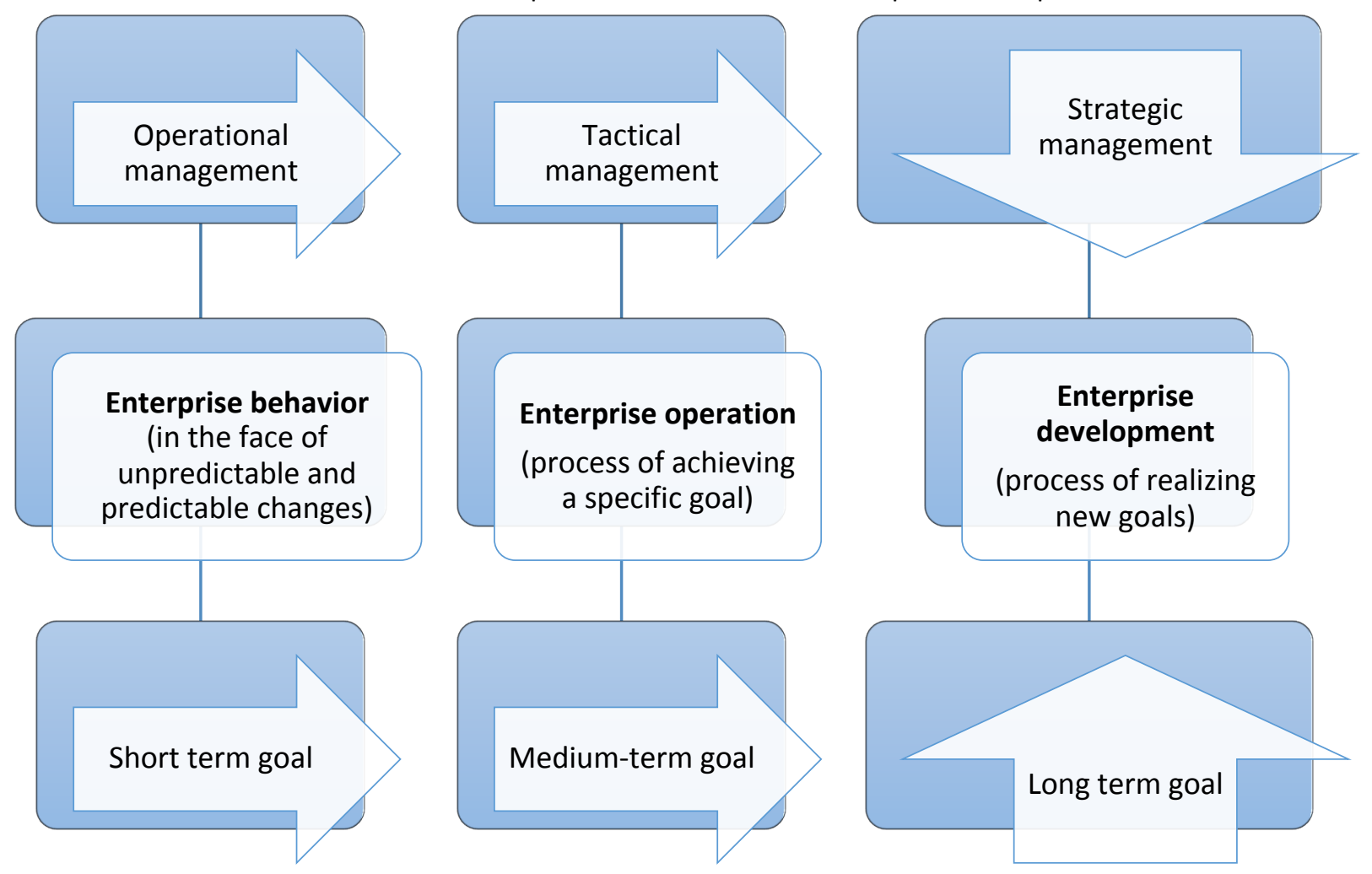

The third block of factors reflects the influence of the external environment on the activities of the enterprise. In this study, it is proposed to determine the influence of the external environment using factors that form the 
market conditions for the operation of an enterprise, namely: the factor of gross value added (GVA) of the industry and the factor of the volume of exports of the industry.

The structure of the predictive model is created by analytical models of the relationships between the selected factors. Building a predictive model is subject to the following rules:

Long-term memory rule. The integral indicators of the components of the enterprise's behavior have a long-term memory, therefore, it is important to use lagged variables when building models;

The rule of openness. The behavior of an enterprise is carried out within the framework of the system "enterprise - industry - national economy" and is an extraverted process, that is, a process conditioned from the outside. In such conditions, it is important to include environmental factors in the structure of the forecasting model of the enterprise's behavior;

Optimality rule. The enterprise in the process of its behavior is trying to achieve the planned standards, that is, to minimize the deviation of the current behavior from the selected optimal values;

The rule of the tactical horizon. Modeling of behavior is carried out in the tactical planning horizon, that is, it covers a time interval from 1 to 3 years;

The rule of hierarchy. The predictive model is a hierarchical model, where at the first level there is a group of factors influencing the factors (resulting) of the following levels.

The construction of a system of models for predicting the behavior of an enterprise is based on determining the relationship of its structural components. The study of the practice of enterprises in the real sector of the economy made it possible to form such a view (Fig. 2).

Figure 2

The relationship of factors of the system of models for predicting

the behavior of an enterprise in a non-stationary environment.

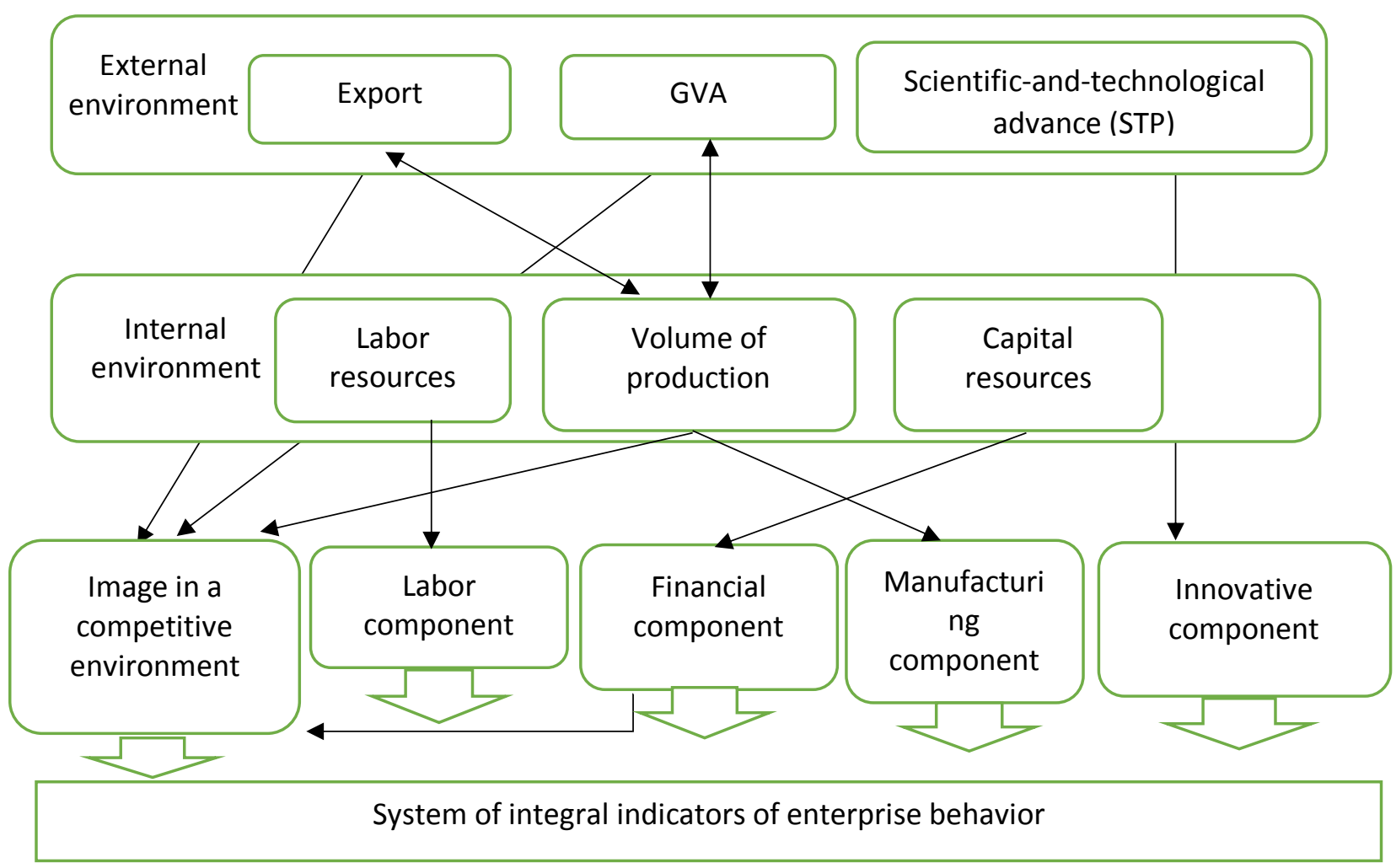


Connections between factors should be determined by analytical dependencies between them in the form of a separate influence or model. Only the relationship between general and partial integral indicators is functional dependence.

As a result of the research, a system of analytical functions has been developed that create the structure of a model for predicting enterprise behavior. Let's consider them in more detail.

The behavior of an enterprise is described by a general integral indicator $\left(I_{p o v}\right)$, which consists of partial integral indicators, proposed by five groups of components and has the following form:

$$
I_{p o v}=a_{1} l_{o b}+a_{2} l_{f i n}+a_{3} l_{\text {proiz }}+a_{4} l_{\text {trud }}+a_{5} l_{i n v}
$$

$I_{o b}, I_{\text {fin }}, I_{\text {proiz }}, I_{\text {trud }}, I_{\text {inv }}$ - partial integral indicators of the level of development of a component of enterprise behavior.

It is proposed to model the proposed components of enterprise behavior using such blocks of models.

Production block.

The production component forecasting model is based on the fact that the partial integral indicator has memory properties. Therefore, to predict this component, it is necessary to take into account the previous values of the integral indicator of the production component. The model looks like this:

$$
I_{\text {proiz }, t}=f\left(I_{\text {proiz }, t-1}, Y_{t}\right) \text {, }
$$

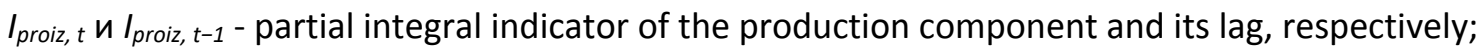

$Y$ - enterprise production volume

To predict the volume of production, it is proposed to use the production function of Cobb - Douglas, which will allow the analysis of the production component of the behavior of the enterprise.

This model looks like this:

$$
Y_{\mathrm{t}}=a_{0} K_{t-1}^{a 1} L_{t-1}^{a 2},
$$

$K_{t-1}^{a 1} L_{t-1}^{a 2}-$ the amount of capital and labor resources of the enterprise at a certain point in time;

$a_{0,} a_{1}, a_{2}$ - model parameters.

The block of scientific and technological progress (STP) and innovation component.

This block characterizes the impact of scientific and technical progress on the behavior of the enterprise. Provided that the scientific and technological progress exerts its influence on the innovative activity of the enterprise and is described by an indicative functional dependence, the study proposes a model for predicting the innovative component of the enterprise:

$$
I_{\text {inv }, t}=a_{3} \exp (p \cdot t),
$$

$I_{\text {inv }, t}$-is a partial integral indicator of the innovative component of the enterprise's behavior; 
$p$-is the growth rate of the integral indicator due to the influence of scientific and technological progress.

The block of financial and labor components.

The integral indicators of the financial and labor components of the enterprise's activity are influenced by the memory factor, which is expressed through the lag variable, and resource factors: the amount of capital (K) for the financial component and the volume of labor costs (L) for the labor component. In general, the model of this block is as follows:

$$
\left\{\begin{array}{l}
I_{f i n, t}=f\left(I_{\text {fin }, t-1}, K_{t-1}\right) \\
I_{\text {trud }, t}=f\left(I_{\text {trud }, t-1}, L_{t-1}\right)
\end{array},\right.
$$

где, $I_{f i n, t}, I_{f i n, t-1}-$ - is a partial integral indicator of the financial component of the enterprise's behavior and its lagged value, respectively;

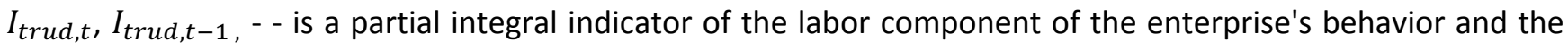
value of its lag, respectively.

The block of an enterprise image in a competitive environment.

The competitive position of an enterprise depends both on the activities of the enterprise itself and on external market conditions. To determine the factors affecting the integral indicator of the company's image in a competitive environment, one should carefully analyze the partial indicators that form this integral indicator. Thus, the capitalization indicators of the enterprise, the growth of assets, their volatility are mainly influenced by the financial indicators of the enterprise, the change in the share of the market segment - by the sales volume indicator. In addition, the integral indicator is influenced by the indicators of the share of exports and the gross value added (GVA) of the industry. Thus, the model looks like this:

$$
I_{o b, t}=f\left(Y_{t}, I_{\text {fin }, t-1}, V d c_{t}, \operatorname{Exp}_{t}\right)
$$

$l_{o b, t}-$ is a partial integral indicator of the company's image in a competitive environment;

$V d c_{t}-$ - is the share of the gross value added of the industry;

$\operatorname{Exp}_{t}-$ is the export share of the industry.

External interaction block.

External interaction in the system "enterprise - industry - national economy" between the enterprise and the external environment is carried out in two directions:

1 direction "enterprise - external environment".

Provided that the enterprise is a component of the industry, then the change in the output of the enterprise affects both the change in the GVA of the value of the industry and the change in exports (if the enterprise is export-oriented);

2 direction "external environment - enterprise".

The external environment creates conjuncture conditions for the functioning of the enterprise. General trends in the industry shape the trends in the behavior of the enterprise. 
To take into account these two areas in the study, it is proposed to use vector autoregressive models (VAR models), which allow using integration effects to study the mutual influence in the "enterprise - external environment" system. In general, the model is shown as follows:

$$
\left\{\begin{array}{c}
Y_{t}=f\left(Y_{t-k}, V d c_{t-k}, E x p_{t-k}\right) \\
V d c_{t}=f\left(Y_{t-k}, V d c_{t-k}, \operatorname{Exp}_{t-k}\right), \\
\operatorname{Exp}_{t}=f\left(Y_{t-k}, V d c_{t-k}, \operatorname{Exp}_{t-k}\right)
\end{array}\right.
$$

$k$ - is the autoregressive order determined using the Granger test.

The advantage of the vector autoregression model is the inclusion of more variables with delays, that is, lagged variables, in the right-hand sides of the equations.

Thus, the proposed system of models for predicting the behavior of an enterprise in an unstable external environment combines models (2) - (7), and has the following form:

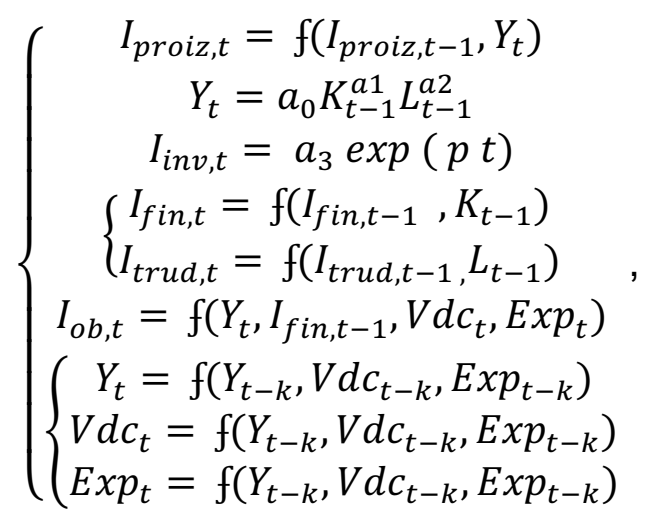

\section{Conclusions}

The study of enterprise behavior on the basis of systemic and predictive approaches allowed us to obtain the following results:

-proposed three groups of factors, which are elements of the forecasting model of enterprise behavior and reflect the resulting factors, controllable factors and environmental factors;

-rules for constructing a predictive model have been developed, which form its methodological basis, which make it possible to take into account various aspects of an enterprise's behavior in the system "enterprise - industry national economy";

-the structure of the model for predicting the behavior of the enterprise was built (Fig. 1), which made it possible to determine the connections between its elements;

-the proposed system of models for predicting the behavior of an enterprise in an unstable external environment in the form of a complex of functional dependencies, which allows analyzing the internal capabilities of an enterprise to changes in the external environment from a systemic point of view.

Further areas of research should be aimed at developing target guidelines for managing the behavior of an enterprise in conditions of fluctuations in the market environment, taking into account its real and potential resource capabilities, as well as the development opportunities of the industry and the national economy. 


\section{Bibliographic references}

Arefieva E.V., Poberezhnaya Z.N. (2019). Intensification of management of the economic behavior of the enterprise in competitive markets. Business inform. No. 12 (503), P, 110-118.

Azaryan E.M., Alekseeva N.I. (2018). Analysis of the factors of influence of the macro-environment on the foreign economic behavior of the enterprise Economics and Management: Problems, Solutions. T. 2. No. 5.P. 84-97.

Budagov A.S., Gagulina N.L., Zhulega I.A., Novikov A.V. (2019). Analysis of institutional transformations of the regional economy. Actual problems of economics and management. No. 1 (21), P. 46-54

Chebykina I.V. (2017). Economic security of the enterprise. New science: from idea to result, №1-1. P. 163-164.

Dementyev V.V. (2018) Enterprise as a system of power. Management sciences in the modern world. T. 1.No. 1. P. 427-432.

Dilovskaya S.E. (2017). Analysis of the economic indicators of the enterprise and decision-making based on the conclusions drawn from the analysis. Eurasian scientific journal. No. 1. P. 17-18.

Goral A.Yu. (2019). Features and importance of organizational culture in modern Russian organizations. In the collection: Modern technologies of personnel management. Materials of the VI International Scientific and Practical Conference. Under the scientific editorship of O.S. Reznikov. P. 146-149

Gutieva A.S. (2017). Enterprise behavior in a hazardous environment. Economy and entrepreneurship. No. 4-2 (81), P. 561-563

Ivanenko A.S. (2017). Socially responsible business: social and psychological signs and characteristics. Scientific Review. Series 2: Humanities. No. 6. P. 123-131.

Lvov L.V. (2020). The influence of individual strategies on organizational behavior. In the collection: Theoretical, methodological and applied problems of the science of man and society in the context of the digital transformation of life. Materials of the International Scientific Conference, P. 43-47.

Maksimenko A.N., Malinina O.Yu. (2018). Modern technologies for assessing and accounting for the effectiveness of entrepreneurial activity. Kant. 2018. No. 3 (28). P. 205-210.

Malinina O.Yu., Kushnareva I.V., Maksimenko A.N. (2019). Methodological foundations of personnel management based on key performance indicators of a commercial enterprise. Bulletin of the Altai Academy of Economics and Law. 2019. No. 1-2. P. 80-85.

Murtazina S.R. (2017). Organizational structure in increasing the competitiveness of the enterprise. In the collection: INTEGRATION PROCESSES IN SCIENCE IN MODERN CONDITIONS. collection of articles of the International Scientific and Practical Conference: in 4 parts, p. 132-135.

Orlov O. O. Sharko V.V. Havenko M. S. Husak L. P. (2020) Developing of competitive strategy for innovative development of enterprise: choosing priorities and tactics. Revista ESPACIOS. ISSN 0798 1015. 41 (34).

Osipov V.A., Shashlo N.V., Kuzubov A.A. (2017) Evaluation of economic sustainability of entrepreneurship on the basis of the valuebased efficiency theory. Espacios, T. 38. № 62. P. 30.

Remadze E.O., Beloborodova T.G., Grigorieva T.V., Abutalipova E.M. (2018). Assessment of the financial condition of an enterprise using a simulation model. Oil and gas business. T. 16.No. 1.P. 120-125. 
Sanakoeva D.K., Gagieva N.A. (2017). Economic security at the enterprise level. Actual problems of the humanities and socio-economic sciences, T. 11. No. S3. P. 125-126.

Shashlo N.V., Kuzubov A.A., Vildeman A.I. (2017) Competitive adaptability as a parameter for assessing investments in enterprise development. Azimuth Research: Economics and Management, Vol. 6. No. 1 (18). P. 209-212.

Subachev S.Yu., Afonina D.V. (2017). Economic security of an enterprise as a condition for its competitiveness. IMSIT Bulletin, No. 1 (69). P. 52-54.

Zhukova I.B., Arefieva V.V. (2017). Analysis of the main financial indicators of the enterprise. In the collection: MODERN APPLIED RESEARCH. materials of the All-Russian conference. South-Russian State Polytechnic University (NPI) named after M.I. Platova, P. 245-249.

Zanikyan B.A., Kuropatkina L.V. (2019). Management of human relations and institutional changes in the enterprise. In the collection: Scientific developments: the Eurasian region. Materials of the international scientific conference of theoretical and applied developments. Managing editor D.R. Khismatullin, P. 7-14.

Zilbershtein O.B., Shklyar T.L., Ershova N.A., Rutskiy E.I. (2017). Methodological foundations of corporate social responsibility management. Internet Journal of Science, T. 9. No. 1.P. 6

Esta obra está bajo una Licencia Creative Commons Attribución-NoCommercial 4.0 International

\section{(cc) EY-NC}

